\title{
Afectación de las rutinas periodísticas de periodistas deportivas mujeres de quito por condicionantes ideológicas, jerárquicas, laborales y la presión social
}

\section{Affectation of the journalistic routines of women sports journalists from Quito due to ideological, hierarchical, labor and social pressure conditions}

\section{Afetação das rotinas jornalísticas de jornalistas esportivas de Quito devido a condições ideológicas, hierárquicas, trabalhistas e de pressão social}

\author{
Nicole Cevallos Rueda ${ }^{1}$ \\ Universidad de Los Hemisferios (Ecuador) \\ nicole.cevallos7@gmail.com
}

Fecha de recepción: 15 de abril de 2019

Fecha de recepción evaluador: 30 de abril de 2019

Fecha de recepción corrección: 15 de mayo de 2019

\begin{abstract}
Resumen
Es importante conocer la afectación de las rutinas periodísticas de periodistas deportivas mujeres, en Quito, por condicionantes ideológicas, jerárquicas, laborales y presión social, desde hace varios años, la sociedad piensa que, solamente, los hombres son quienes

\footnotetext{
1 Nicole Cevallos Rueda. Licenciada en Comunicación por la Universidad de Los Hemisferios. FreeLancer. Conocimientos y experiencia en locución en Área Deportiva; Coordinación de Edición de Sello Editorial Razón y Palabra; Creación de Guiones/ Producción Ejecutiva en Showbit; Manejo del área de comunicación y publicidad en Cistec. ORCID: https://orcid.org/0000-0001-6161-1022
} 
pueden realizar este trabajo. Las periodistas a las que se entrevistó confirmaron que aún existe este pensamiento machista en la sociedad. Durante la investigación, se encontró que la preparación y rutinas periodísticas que realizan, ayudan a las periodistas a eliminar las condicionantes laborales, ideológicas, jerárquicas y sociales, dejando un margen nulo de error en su trabajo, esto quiere decir, que se encuentran tan bien preparadas para realizar su trabajo, que, en su mayoría, no comete errores al informar a la audiencia. Por lo tanto, se ha demostrado que las periodistas deportivas mujeres se han ganado el espacio y respeto en el ámbito social y por parte de la audiencia, haciéndolas formar parte del periodismo deportivo en Quito.

Palabras clave: Rutinas periodísticas, condiciones laborales, condiciones ideológicas, condiciones jerárquicas, presión social, formación.

\begin{abstract}
The effects of journalistic routines of women involved in sports journalism in Quito due to ideological, hierarchical, labor and social pressure conditions is important for society since it is usually considered that, because of being women, they cannot work in the journalism field. For several years, society has considered that only men are the ones who can perform this task. The interviewed journalist women made it known that this sexist thought does exist even in society, but, with the training they have had over the years, they have shown that they can do sports journalism. As a main idea, it was found that the formation and journalistic routines women perform has helped journalists to eliminate labor, ideological, hierarchical and social conditions, leaving a margin of zero errors in their work. Therefore, it has been demonstrated that female sports journalists have earned space and respect in the social field and about the audience, it has made them part of sports journalism in Quito.
\end{abstract}

Keywords: Journalistic routines, labor conditions, ideological conditions, hierarchical conditions, social pressure, training.

\title{
Resumo
}

Os efeitos das rotinas jornalísticas das mulheres envolvidas no jornalismo esportivo em Quito devido a condições ideológicas, hierárquicas, trabalhistas e sociais são importantes para a sociedade, uma vez que geralmente se considera que, por serem mulheres, elas não podem trabalhar no campo do jornalismo. Por vários anos, a sociedade considerou que apenas os homens são os que podem executar essa tarefa. As jornalistas entrevistadas informaram que esse pensamento sexista existe mesmo na sociedade, mas, com o treinamento que tiveram ao longo dos anos, mostraram que podem fazer jornalismo esportivo. Como idéia principal, verificou-se que as rotinas de formação e jornalismo desempenhadas pelas mulheres ajudaram jornalistas a eliminar condições trabalhistas, ideológicas, hierárquicas e sociais, deixando uma margem de zero erro em seu trabalho. Portanto, foi demonstrado que as jornalistas esportivas conquistaram espaço e respeito no campo social e sobre o público, e as tornaram parte do jornalismo esportivo em Quito. 
Palavras-chave: Rotinas jornalísticas, condições de trabalho, condições ideológicas, condições hierárquicas, pressão social, treinamento.

\section{Introducción}

Hay que tomar en cuenta que la sociedad ecuatoriana se ha visto acaparada por una sociedad machista, teniendo en cuenta que:

en diciembre de 2016 el ingreso laboral promedio de las mujeres fue de $\$ 287,18$ mientras que el de los hombres fue de $\$ 367,7$, lo que representa una relación del primero con el segundo de aproximadamente el $78 \%$. Esto permite vislumbrar que la problemática de la discriminación por género no está todavía resuelta (Benítez \& Espinosa, 2018, p. $5)$.

Es probable que, a pesar de la preparación de las mujeres en el Ecuador, la sociedad en la que se desarrollan no realiza de manera justa una distribución laboral para los profesionales, tomando en cuenta que los hombres se han visto beneficiados por esta sociedad. Sin embargo, tanto hombres como mujeres merecen el mismo trato justo en cualquier aspecto de la sociedad, una sociedad que no se vea marcada por el género de las personas, sino su preparación para cada puesto de trabajo.

Debido a que la sociedad ecuatoriana se ha visto identificada por creer que el fútbol solo se practica por los hombres, $\mathrm{y}$, por ende, ellos son quienes deben relatarlo. En la actualidad, varias periodistas deportivas mujeres en los distintos medios y soportes mediáticos han demostrado que existe profesionalismo y preparación para llegar al puesto donde se encuentran. No es necesario que los hombres sean quienes se encarguen de todo este trabajo, sino, tanto hombres como mujeres pueden realizarlo. Además, es importante entender que, muchas veces, es la sociedad la que debe cambiar.

No se puede vivir con un pensamiento pasado, es por eso por lo que en el Ecuador se ha desarrollado una política de no discriminación, en la cual, las mujeres puedan tener un trabajo digno, debido a su preparación académica como personal y así, esta no se vea distorsionada por una ideología de género de una sociedad antiguamente machista:

Se produce discriminación directa cuando la diferencia de trato se funda directa y expresamente en distinciones basadas de manera exclusiva en el sexo y en características del hombre y de la mujer que no pueden justificarse objetivamente e indirecta cuando la ley, el principio o el programa no tienen apariencia discriminatoria, pero producen discriminación en su aplicación (Vásquez \& Rivadeneira, 2012, p. 16).

De esta manera, existe un problema a responder: ¿en qué medida se ven afectadas las rutinas periodísticas de periodistas deportivas mujeres de Quito por las condicionantes ideológicas, jerárquicas, laborales y la presión social?

Los objetivos de la investigación fueron: a) Determinar la práctica de periodistas deportivas mujeres, su formación, sus logros y los problemas a los que se enfrentan. b) Señalar cuáles son las rutinas periodísticas de periodistas deportivas mujeres en los distintos medios. c) Evaluar cuáles son las condicionantes ideológicas, jerárquicas, laborales y la presión social en las rutinas periodísticas de periodistas mujeres deportivas. 


\section{Marco referencial}

\section{Formación de periodistas deportivas mujeres}

La lectura se la hace diariamente, no puede haber información por parte de un periodista si este no se prepara diariamente. Una de las rutinas más importantes entonces, es aquella que se basa en la formación continua. Formación continua por el hecho de que un periodista necesita educarse, leer y aprender a verificar entre información real y fake news o noticias falsas. Sin embargo, las periodistas deportivas mujeres deben aprender a informarse y educarse de tal manera que su margen de error sea nulo. Fake news se define como:

Las fake news son muy poderosas. Tanto, que pueden trastornar a largo plazo nuestra capacidad de discernir entre verdad y mentira. El efecto 'verdad ilusoria' fue estudiado hacia finales de los años 70 y se llegó a demostrar que una mentira repetida la suficiente cantidad de veces se convertirá en verdad. Más aún, es más fácil confiar en una mentira popular que en una verdad desconocida (Fernández, 2017, párr. 1).

Si los periodistas son aquellos que brindan la información, esta siempre debe ser verificada en distintas fuentes y por la capacidad de discernir la realidad de lo falso del periodista. Sin embargo, internet se ve lleno de personas que dan información, pero al no ser verificada, queda a un lado de las noticias.

Es importante entender que son los medios de comunicación aquellos que proporcionan la información necesaria en cualquier soporte. La responsabilidad del periodista recae sobre la información que brinda a las personas. Es por eso que:

Los medios de comunicación poseen una enorme responsabilidad social ya que en su tarea continua de informar y entretener también desempeñan una importante labor educadora y formativa al transmitir en su discurso, de forma más o menos explícita, una serie de pautas lingüísticas, ideológicas y de comportamiento que llegan a influir decisivamente en las maneras de decir, hacer y pensar de los ciudadanos (J. L. Rojas, 2010, p. 2).

Sin embargo, esta labor que cumplen no debe tener errores, se determinan errores a aquellas fallas que pueden tener los periodistas, ya sea por la mención a un deportista o por dictaminar de manera errónea un resultado, etc., porque así, los ciudadanos tendrán información relevante y que les brinde un aprendizaje correcto.

Por otro lado, dentro de la formación de los periodistas, cabe recalcar la importancia de cada uno de los medios de comunicación. Porque son estos medios de comunicación los que brindan la información a la sociedad, debido a que, sin la preparación necesaria para cada una de las periodistas en los campos que se desarrollan, la sociedad a la que se dirigen no tendrá la información correcta. Además, si se habla del periodismo deportivo:

El estudio de relaciones del binomio deporte y tecnología supone, por tanto, el reconocimiento de dos realidades que movilizan a un gran número de personas que consumen contenidos deportivos producidos y asimilados con aplicaciones y recursos 
tecnológicos (cámaras digitales, webcam, ordenadores, tabletas, smartphones, buscadores de internet, programas informáticos, contenidos multimedia, hipervínculos, blogs, redes sociales, wikis) (Méndez, 2015, p. 450).

Son los periodistas los que necesitan exigir qué recursos se utilizarán debido a un criterio propio, basado en el trabajo que realizan y en lo que creen que es apto para la recepción de la información.

Por otro lado, se menciona que esto tiene toda la información necesaria, porque el periodismo deportivo va de la mano con las tecnologías. A pesar de las licenciaturas en periodismo o comunicación, es importante que cada uno de los periodistas tenga una formación académica propia, tomando en cuenta que, con el internet, la obtención de información se ha vuelto cada vez menos complicada. Esto se da porque aquí, cada persona puede leer, informarse o investigar y así, cada una de las personas de las diferentes sociedades, será capaz de recibir una información que no podrá recibir en otro lado. Debido a la manera en que la sociedad está establecida, el uso de internet y aparatos electrónicos ha incrementado cada forma de consumir información por parte de las personas.

Tal vez los medios actuales han permitido que las personas se conviertan en periodistas porque "las nuevas tecnologías de la comunicación, TIC, están produciendo una revolución que convierte a los lectores, radioyentes y televidentes en una clase de comunicadores que juegan un papel análogo al tan conocido de los periodistas" (Proaño, 2005 , p. 1). Cabe mencionar que debe existir una diferencia notable en aquellas personas que simplemente informan a través de internet, con aquellos que brindan noticias e información debidamente investigada y comprobada.

\section{Rutinas periodísticas llevadas a cabo para el periodismo deportivo}

Vivimos en una sociedad donde el deporte se lo vive día a día, minuto a minuto. Las diferentes sociedades le han ido dando mucha importancia: "desde el punto de vista de la audiencia, muchos internautas, utilizan las redes sociales, en algunos casos, sin saber el verdadero concepto de la tecnología que usan" (Vivar \& Miguel, 2009, p. 74). Las personas deben aprender a diferenciar qué tipo de información consumen, no se debe tomar como información a lo primero que aparece en pantalla ni en redes sociales.

Es importante recalcar que las rutinas periodísticas en este ámbito se ven más afectadas porque en las noticias se tiene una guía de aquello que se debe decir, más una parrilla de contenidos que se transmitirá. Pero en el periodismo deportivo no se puede definir lo que pasará, la inmediatez cambia minuto a minuto con lo que sucede dentro y fuera de la cancha, es por eso, que los periodistas tienen que estar preparados para contrastar información y llevar algo verdadero a la audiencia.

Sin embargo, se define a una de las rutinas periodísticas como:

la lectura diaria de los principales periódicos del planeta, en sustitución de la lectura de los ejemplares en papel. Esta práctica es especialmente destacable en las secciones de internacional. Cabe destacar, sin embargo, que, en contadas ocasiones la 
información obtenida de la consulta de esos periódicos tiene una incidencia directa en la redacción de las noticias del día (Masip, 2013, p. 569).

Esto se da por el hecho de que un periodista necesita educarse a sí mismo aparte de la educación que ha recibido en los diferentes niveles de titulaciones. Si un periodista no es capaz de llevar una rutina de autoeducación, no sabrá informarse día a día, por lo tanto, no podrá brindar información a la audiencia.

\section{Condicionantes en las rutinas periodísticas del periodismo deportivo en mujeres}

No debería existir condicionantes, si es posible decirlo. Las condicionantes no solo afectan al periodista, sino al trabajo que realiza, por lo tanto, "se puede decir que el género no solo articula estos modelos de referencia, sino que también enmarcan campos de acción: en sus prácticas sociales concretas, los hombres y mujeres reproducen las representaciones de feminidad y masculinidad" (Pedraza, 2012, p. 4). Siendo así, que se define una diferencia de género donde la masculinidad y la feminidad se ven envueltas para la selección de personas. Suponiendo que así una persona será mejor preparada que otra, o, incluso, que, por el simple hecho de ser mujer, no podrá realizar el mismo trabajo que realiza un hombre.

La mayor condicionante que se puede mencionar es la condicionante de género, que, por ende, repercutirá en condicionantes laborales y jerárquicas, llevadas de la mano de una presión social mayor por el simple hecho de ser mujeres. No solo es el hecho de que exista una presión, sino:

el mantenimiento de estos estereotipos (hombre-fortaleza, mujer-delicadeza) ha generado un rechazo histórico hacia el ejercicio físico violento practicado por mujeres. El deporte resulta arriesgado según el argumento de la inferioridad biológica femenina, de acuerdo con el cual las capacidades físicas, motoras e incluso psicológicas no pueden desarrollarse al mismo nivel que los varones (Pedraza, 2012, p. 7).

Dado que, si una mujer está preparada, debe tener toda la apertura necesaria para trabajar en el medio que desee, con esto, no se trata de definir que, si una periodista desea trabajar en un medio definido, lo hará simplemente por tener un título, sino, que debido a la preparación que posee, tanto periodistas deportivas mujeres como hombres, deberán poder trabajar en medios importantes, sin llevar una discriminación en ámbitos laborales ni profesionales.

Es por esto por lo que el trabajo que realizan periodistas deportivas mujeres no solo se evidencia en la mayor capacidad que deben tener de almacenar información, sino que muchas de ellas incluso practican el deporte. Es decir, el periodismo va de la mano con el fútbol practicado como deporte, siendo así, que incluso esta puede ser una de las rutinas periodísticas que es llevada a cabo por las periodistas deportivas mujeres.

Por otro lado, definiendo el término "feminización", que quiere decir que se observa la "relación a las mujeres en su rol como trabajadoras, se les atribuye una actitud más conflictiva que la de los varones frente al reclamo, pero a la vez se valora la 
responsabilidad, el compromiso con la tarea que están haciendo y la constancia en los puestos de trabajo que desempeñan" (Mingo, 2005, p. 14). Se observa que este término no es mencionado de una mala manera, sino, de manera en que tanto hombre como mujer tengan las mismas oportunidades de trabajo. Ambos deben aprender a ser los mejores profesionales, por el simple hecho de que la audiencia que poseen necesita excelencia en la selección de información además de adquirir información verdadera.

Además, ya no se vería una inferioridad anteriormente planteada por otras sociedades como inferioridad biológica, sino, se ven las capacidades y la disciplina que cada una de las mujeres posee. Además de la constancia, porque sin ella, no lograrían demostrar que son tan capaces de realizar lo mismo que realizaría un hombre. Pero:

entre la avalancha de cambios sociales del siglo XX, posiblemente, el más significativo y duradero ha sido la irrupción de las mujeres en la escena pública y en múltiples esferas del quehacer humano. La comunicación es una de estas nuevas áreas de potencial realización de las mujeres (Burch, 1995, p. 1).

Siendo así que para el siglo XXI y con el avance de la tecnología, las periodistas tienen toda la acogida necesaria para brindar su trabajo a los medios. De tal manera, dejan claro que no por el hecho de ser mujeres merecen menos respeto, y aunque la presión sobre ellas recaiga el doble que, sobre un hombre. Si se tiene una igualdad de pensamiento, se tendrá igualdad de condiciones y no habrá discriminación en ningún ámbito. Esto se menciona porque se observa que el periodismo deportivo sigue siendo el mismo del anterior siglo, lo que ha realizado, es una adaptación a la web 2.0 y a medios no tradicionales, como lo son las redes sociales o los cibermedios. Pero, a pesar de esto, la manera en la que se realiza este tipo de periodismo sigue siendo la misma.

\section{Metodología}

La investigación fue cualitativa porque se realizaron entrevistas con base en un cuestionario semiestructurado a cuatro periodistas deportivas mujeres. Esto abrió paso a la recolección de información detallada con base en la pregunta planteada al inicio: ¿en qué medida se ven afectadas las rutinas periodísticas de periodistas deportivas mujeres de Quito por las condicionantes ideológicas, jerárquicas, laborales y la presión social? Fue posible definir si los condicionantes elegidos afectan o no a las rutinas periodísticas que las mismas personas llevan a cabo.

La investigación se centró en el trabajo de periodistas deportivas mujeres que se encuentran en Quito en radio, prensa, televisión y cibermedios. Se realizaron cuatro entrevistas a periodistas deportivas mujeres que laboren actualmente en los soportes informativos de radio, prensa, televisión y cibermedios. Las entrevistadas fueron a Johana Calderón (televisión), Soledad Rodríguez (radio), Ana Rosero (cibermedios) y Martha Córdova (prensa), la entrevista se ajustó a la decisión de las periodistas, en presentar su nombre en la investigación.

Tabla 1. Características sociodemográficas 


\section{Variables Sociodemográficas}

\begin{tabular}{lll}
\hline Sexo: & Femenino & 4 \\
\hline Edad: & Johana & 25 \\
& Anny & 27 \\
& Soledad & 30 \\
& Martha & 52 \\
& \\
\hline Nacionalidad: & Ecuatoriana & 4 \\
\hline
\end{tabular}

Fuente: elaboración propia.

Tabla 2. Características Laborales

Variables Laborales

\begin{tabular}{lll}
\hline Soporte mediático: & Cibermedio & 1 \\
& Prensa & 1 \\
& Radio & 1 \\
& Televisión & 1 \\
\hline Tipo de contrato: & Tiempo Completo & 3 \\
& Servicios Profesionales & 1
\end{tabular}

Fuente: elaboración propia.

Tabla 3. Características formativas de las entrevistadas

\section{Variables Formativas}

\begin{tabular}{lcc}
\hline Licenciatura en comunicación: & Sí & 4 \\
& No & 0 \\
\hline Otra licenciatura: & Sí & 0 \\
& No & 4 \\
\hline
\end{tabular}




\begin{tabular}{lcc|}
\hline Título de cuarto nivel en comunicación: & Sí & 1 \\
& No & 3 \\
\hline Formación continua: & Sí & 4 \\
& No & 0 \\
\hline
\end{tabular}

Fuente: elaboración propia.

Johana Calderón es una periodista de 25 años que trabaja actualmente en 3 medios, como son radio, televisión e internet. El rol organizacional que posee es de periodista y comentarista deportiva. No posee una dedicación exclusiva ya que trabaja en distintos medios. Su tipo de contrato se basa en un contrato de medio tiempo. Ha obtenido una licenciatura en comunicación sin la obtención de otra licenciatura o título de 4to. nivel. A pesar de esto posee una formación continua todos los días. Anny Rosero tiene 27 años, de nacionalidad ecuatoriana, es una periodista que trabaja en 3 de todos los medios: radio, televisión e internet. El rol organizacional que realiza es de directora de programa, coordinación y organización de proyectos. No posee un contrato de dedicación exclusiva, a pesar de tener un contrato de tiempo completo en cada uno de los medios. Posee una licenciatura en Comunicación y continúa formándose día a día.

Martha Córdova tiene 52 años, de nacionalidad ecuatoriana es una periodista que se dedica únicamente a la prensa. Teniendo como rol organizacional la redacción de la sección de Deportes, además de un contrato de exclusividad y tiempo completo con $E l$ Comercio desde el año 2014. Posee un título de licenciatura en comunicación y un título de 4to nivel, magister en docencia universitaria. Además, su formación es continua. Soledad Rodríguez tiene 30 años, de nacionalidad ecuatoriana. Es una periodista deportiva de radio, teniendo un rol organizacional de comentarista y reportera deportiva. Tiene un contrato de exclusividad en la radio La Redonda donde su tipo de contrato es de prestación de servicios profesionales. Posee una licenciatura en comunicación y una formación continua día a día.

La herramienta metodológica que se usó en la elaboración fue la entrevista semiestructurada, esto quiere decir, que se utilizó un cuestionario que dio alternativas de respuesta que sean predefinidas, además de respuestas abiertas, en aquellas que la persona entrevistada tuvo la capacidad de contestar con total libertad.

En este proyecto se definieron cuatro condicionantes de la labor informativa. Estos fueron: a) ideológicos, que son aquellos que consideran las presiones que pueda tener el informador en relación con la línea editorial que va de acuerdo con el medio en el que trabajan, aunque también puede verse en la ideología de la empresa; b) jerárquicos, se ven relacionados con los efectos que posean las periodistas y su trabajo, es una coacción que proviene de la jerarquía organizacional; c) laborales, aquellos que afecten a la inmersión laboral de la periodista y su estabilidad en el puesto de trabajo, inclusive, 
la situación salarial; y d) presión social, que se refiere a la presión que tiene la sociedad y la audiencia para la periodista y el medio en el que trabaja, para la instalación en el escenario informativo.

Los indicadores fueron: a) Rutinas periodísticas. b) Condiciones laborales. c) Condiciones ideológicas. d) Condiciones jerárquicas. e) Presión social.

Por lo tanto, dentro de cada uno de los temas, se encontrarán las siguientes palabras claves: a) Trabajo realizado, formación y experiencia en el trabajo. b) Ideológicas, jerárquicas y laborales. c) Medio de trabajo, cultura prevaleciente y prejuicios laborales.

\section{Hallazgos}

Dentro de este aspecto, se define por entrevistadas; cada una de ellas ha aceptado el uso de su nombre. Es un resumen detallado con base en las preguntas establecidas en el primer cuestionario a ser aplicado. Posteriormente, se realizó una entrevista con cada una de ellas.

\section{Rutinas periodísticas}

Dentro de rutinas periodísticas se trataron las preguntas $1,2,10$ y 11 que se encuentra en la parte de anexos.

Tabla 4: Rutinas periodísticas

\begin{tabular}{|c|c|c|}
\hline Entrevistado & Pregunta & Respuesta \\
\hline $\begin{array}{l}\text { Soledad } \\
\text { Rodríguez }\end{array}$ & $\begin{array}{l}\text { ¿Por qué su inclinación al periodismo } \\
\text { deportivo? }\end{array}$ & $\begin{array}{l}\text { Desde mi infancia crecí en un entorno } \\
\text { muy deportivo con padres fanáticos del } \\
\text { fútbol y talento especial para su práctica } \\
\text { y entendimiento. }\end{array}$ \\
\hline \multirow[t]{2}{*}{$\begin{array}{l}\text { Soledad } \\
\text { Rodríguez }\end{array}$} & $\begin{array}{l}\text { ¿Qué rutinas periodísticas se llevan a } \\
\text { cabo en el periodismo deportivo? } \\
\text { ¿Cómo se hace la selección de la } \\
\text { información? }\end{array}$ & $\begin{array}{l}\text { La información siempre se elige en base a } \\
\text { la agenda que nos entrega tanto la } \\
\text { coyuntura nacional como las prioridades } \\
\text { en base al target del medio. }\end{array}$ \\
\hline & $\begin{array}{l}\text { ¿Cómo se escoge la producción del } \\
\text { material y la emisión de pautas? }\end{array}$ & $\begin{array}{l}\text { De la producción y comercialización se } \\
\text { encargan áreas específicas que manejan } \\
\text { los contenidos direccionados por el jefe } \\
\text { del medio y por la administración } \\
\text { institucional, respectivamente. }\end{array}$ \\
\hline
\end{tabular}




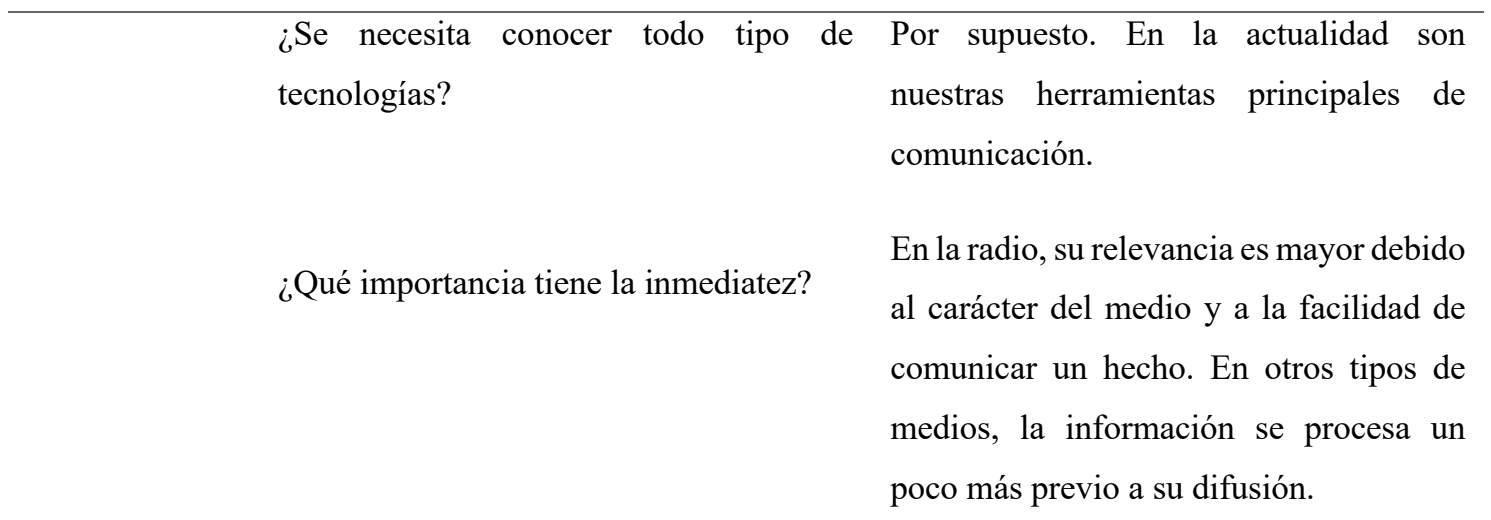

\begin{tabular}{lll} 
Soledad & ¿Se posee una estabilidad salarial? & Eso depende del medio. En radios, por \\
Rodríguez & ejemplo, es muy común que sus \\
& directores contraten bajo la figura de \\
& cupos de publicidad y ahí, no existe una \\
& garantía. \\
\hline
\end{tabular}

$\begin{array}{ll}\text { Soledad } & \text { ¿Existe la estabilidad en el puesto de En la mayoría de los casos, sí. } \\ \text { Rodríguez } & \text { trabajo? }\end{array}$

\begin{tabular}{l|l} 
Martha & ¿Por qué su inclinación al periodismo \\
Córdova & Con mi padre miré todos los partidos del \\
deportivo? & Mundial de Fútbol Argentina 1978. \\
& Quedé cautivada por la pasión, alegrías, \\
& euforias y sentimientos. Aprendí de \\
& gambetas, goles y goleadas. Tenía 12 \\
& años. Ahí supe que el fútbol y el deporte \\
& serían parte de mi vida.
\end{tabular}

Martha ¿Qué rutinas periodísticas se llevan a Eduardo Galeano, escritor uruguayo, dice

Córdova cabo en el periodismo deportivo? que el fútbol es lo más importante de los menos importante. Yo diría que tiene un mundo lleno de cosas importantes, sino porque el país se paraliza cuando juega la Selección.

¿Cómo se hace la selección de la información

Como el periodismo en general, quien lo ejerce debe tener una agenda noticiosa, con los hechos coyunturales y también abordar temas, que le suelen ser incómodos para los gobernantes $\mathrm{y}$ autoridades.

Me gusta mucho abortar a la persona más que al personaje. Descubrir la esencia del 
¿Cómo se escoge la producción del deportista, qué limitaciones venció con material y la emisión de pautas?

persistencia y pasión.

¿Se necesita conocer todo tipo de

Por la Coyuntura informativa. Por el interés de encontrar personajes importantes. Por temas que deben ser tecnologías?

abordados y que tienen gran interés, por ejemplo, la eliminación del Ministerio del Deporte y sus consecuencias.

Por el eje que se debió establecer antes de la reportería. Por el material que se recogió y por las pruebas que se posea antes de una denuncia.

Ahora sí, es indispensable para ser un periodista competitivo en el mercado.

¿Qué importancia tiene la inmediatez?

La inmediatez debe guardar los mismos fundamentos noticiosos y éticos: la verificación y la comprobación. No se puede decir cualquier cosa por la inmediatez. El patrimonio más valioso de un periodista es la credibilidad. No la puedes poner en juego por la inmediatez.

\begin{tabular}{lll}
\hline $\begin{array}{l}\text { Martha } \\
\text { Córdova }\end{array}$ & ¿Se posee una estabilidad salarial? & Sí. \\
\hline Martha & ¿Existe la estabilidad en el puesto de & Sí. \\
Córdova & trabajo?
\end{tabular}

\begin{tabular}{lll}
\hline Anny Rosero & $\begin{array}{l}\text { ¿Por qué su inclinación al periodismo } \\
\text { deportivo? }\end{array}$ & $\begin{array}{l}\text { Sin duda alguna el periodismo deportivo } \\
\text { en las mujeres es un campo aún no } \\
\text { explotado en su totalidad, a parte de la } \\
\text { afinidad que se tiene hacia los deportes en } \\
\text { general y en especial al rey de los } \\
\text { deportes, el fútbol. }\end{array}$ \\
\hline Anny Rosero & ¿Qué rutinas periodísticas se llevan a & De acuerdo con la información \\
& cabo en el periodismo deportivo? & $\begin{array}{l}\text { coyuntural que este en el medio, es decir, } \\
\text { partidos de temporada o copas } \\
\text { internacionales. }\end{array}$
\end{tabular}




\begin{tabular}{|c|c|c|}
\hline & $\begin{array}{l}\text { ¿Cómo se hace la selección de la } \\
\text { información? }\end{array}$ & $\begin{array}{l}\text { Copas más importantes, jugadas } \\
\text { destacadas, competencias. }\end{array}$ \\
\hline & & Sí, es fundamental. \\
\hline & $\begin{array}{l}\text { ¿Cómo se escoge la producción del } \\
\text { material y la emisión de pautas? } \\
\text { ¿Se necesita conocer todo tipo de } \\
\text { tecnologías? }\end{array}$ & $\begin{array}{l}\text { Juega un papel muy importante, por } \\
\text { ejemplo, a nivel futbolístico, el mantener } \\
\text { informado al oyente o televidente del } \\
\text { minuto a minuto del encuentro entre dos } \\
\text { equipos es básico, ya que en cuestión de } \\
\text { segundos el marcador puede cambiar o } \\
\text { una jugada de un giro total al partido. }\end{array}$ \\
\hline & ¿Qué importancia tiene la inmediatez? & \\
\hline Anny Rosero & ¿Se posee una estabilidad salarial? & $\begin{array}{l}\text { Como todo al principio quizá no, pero es } \\
\text { un trabajo de esfuerzo y dedicación en } \\
\text { donde poco a poco se va haciendo } \\
\text { conocido el trabajo que se realiza y } \\
\text { nuestro profesionalismo será } \\
\text { recompensado no solo económicamente. }\end{array}$ \\
\hline Anny Rosero & $\begin{array}{l}\text { ¿Existe la estabilidad en el puesto de } \\
\text { trabajo? }\end{array}$ & $\begin{array}{l}\text { No se puede hablar de una estabilidad } \\
\text { total, ya que en sí dentro del medio se } \\
\text { debe ser consciente que todos somos } \\
\text { pasajeros y que incluso si se presenta una } \\
\text { oferta mucho mejor, debemos buscar el } \\
\text { medio en el cual podamos desarrollarnos } \\
\text { mejor y crecer a nivel profesional. }\end{array}$ \\
\hline $\begin{array}{l}\text { Johana } \\
\text { Calderón }\end{array}$ & $\begin{array}{l}\text { ¿Por qué su inclinación al periodismo } \\
\text { deportivo? }\end{array}$ & $\begin{array}{l}\text { Se da por mi gusto, mi pasión, mi amor } \\
\text { hacia el fútbol donde veía fútbol con mi } \\
\text { padre. Yo lo practico desde los } 7 \text { años. El } \\
\text { periodismo deportivo fue la oportunidad } \\
\text { de trabajar en el campo del rey de los } \\
\text { deportes. }\end{array}$ \\
\hline $\begin{array}{l}\text { Johana } \\
\text { Calderón }\end{array}$ & $\begin{array}{l}\text { ¿Qué rutinas periodísticas se llevan a } \\
\text { cabo en el periodismo deportivo? }\end{array}$ & $\begin{array}{l}\text { Leer bastante, aunque eso se debería } \\
\text { aplicar en cualquier ámbito del } \\
\text { periodismo. Me informo en el tema de } \\
\text { jugadores, estadística, historia. Ir a la } \\
\text { fuente, conversar con ellos. Conversar }\end{array}$ \\
\hline
\end{tabular}




\begin{tabular}{|c|c|c|}
\hline & & $\begin{array}{l}\text { con las fuentes y contrastar la } \\
\text { información que se encuentra en redes } \\
\text { porque por la inmediatez no se debe dejar } \\
\text { llevar las personas. El no contrastar la } \\
\text { información es un error que cometemos } \\
\text { casi todos. }\end{array}$ \\
\hline & $\begin{array}{l}\text { ¿Cómo se hace la selección de la } \\
\text { información? }\end{array}$ & $\begin{array}{l}\text { La selección de información es } \\
\text { directamente con la fuente, no fiarse de } \\
\text { redes sociales. }\end{array}$ \\
\hline & $\begin{array}{l}\text { ¿Cómo se escoge la producción del } \\
\text { material y la emisión de pautas? } \\
\text { ¿Se necesita conocer todo tipo de } \\
\text { tecnologías? }\end{array}$ & $\begin{array}{l}\text { La inmediatez es importante ya que por } \\
\text { las redes sociales hay que acoplarse, } \\
\text { informar rápidamente pero no dejar de } \\
\text { primar información verídica. Pensando en } \\
\text { dar información real y verificada. Ante } \\
\text { todo, está la credibilidad del periodista } \\
\text { con la audiencia. }\end{array}$ \\
\hline & ¿Qué importancia tiene la inmediatez? & \\
\hline $\begin{array}{l}\text { Johana } \\
\text { Calderón }\end{array}$ & ¿Se posee una estabilidad salarial? & $\begin{array}{l}\text { Un periodista deportivo debe saber que } \\
\text { no va a ser millonario y que desde el día } \\
\text { que comienza esta profesión debe saber } \\
\text { que lo hace por pasión. Porque no es muy } \\
\text { bien remunerado el periodista, pero sí se } \\
\text { puede llegar a vivir bien y tener un salario } \\
\text { estable. Muchas veces en radios no se } \\
\text { tienen sueldos fijos pero el periodista } \\
\text { deportivo en Ecuador no es valorado. }\end{array}$ \\
\hline $\begin{array}{l}\text { Johana } \\
\text { Calderón }\end{array}$ & $\begin{array}{l}\text { ¿Existe la estabilidad en el puesto de } \\
\text { trabajo? }\end{array}$ & $\begin{array}{l}\text { No hay una estabilidad por lo que en las } \\
\text { mayorías de lugares suelen dar cupos de } \\
\text { publicidad, donde no se tienen salarios } \\
\text { fijos, por lo cual no se posee algo fijo. }\end{array}$ \\
\hline
\end{tabular}

\section{Fuente: elaboración propia.}

Se puede observar que cada una de las entrevistadas ha vivido en un ámbito donde se ha desarrollado en el entorno del fútbol desde muy corta edad. Cabe recalcar que en años anteriores las mujeres no eran bien vistas o se creía que no sabían de deportes tanto como un hombre, ni qué decir del fútbol, sin embargo, las entrevistadas demostraron no verse afectadas por ese pensamiento. Se creía que el fútbol era un deporte en el que solo se pueden desarrollar los hombres y no las mujeres. Actualmente, las mujeres se han 
abierto paso en este ámbito demostrando que están a la altura o mejor preparadas que los mismos hombres. Además, hay que tomar en cuenta que en este ámbito se habla de las rutinas periodísticas que cada una de las periodistas lleva a cabo y de la función de las redes además de la estabilidad salarial y de su puesto de trabajo.

Rodríguez menciona que "se habla de una selección de información, toma como guía a la agenda que se les entrega de acuerdo con la coyuntura nacional, mencionando que esto se basa en el público objetivo que tiene cada medio" (S. Rodríguez, entrevista, 2018). A diferencia de Calderón, que menciona: "la selección de información es directamente con la fuente, no fiarse de redes sociales. La inmediatez es importante ya que por las redes sociales hay que acoplarse, informar rápidamente pero no dejar de primar información verídica" (J. Calderón, entrevista, 2018). Siendo así, que algo importante que se puede destacar en esto, es que se debe hablar de algo que acompañe a todas las personas.

Córdova menciona que "en prensa, la inmediatez debe llevarse a cabo con un riguroso proceso de guardar los fundamentos noticiosos y éticos, por lo tanto, todo tema debe ser verificado y comprobado, no por el hecho de poseer inmediatez, se puede mencionar cualquier cosa porque se pone en juego a la credibilidad del periodista" (M. Córdova, entrevista, 2018); mientras Rosero menciona "la importancia de la inmediatez, porque en el nivel futbolístico, el mantener informado al oyente o televidente del minuto a minuto en los partidos que se juegan es lo primordial, debido a que en cuestión de segundos los marcadores y jugadas cambian, dándoles giros inesperados a los partidos" (A. Rosero, entrevista, 2018). Y, a pesar de que todo se ve favorecido porque este deporte es acogido por todos los medios. Mencionan que el puesto de trabajo no es fijo y que, para lograr ser fijos, se debe demostrar que te mereces ese puesto.

\section{Condicionantes Laborales}

Dentro de condicionantes laborales se trataron las preguntas 3 y 4 que se encuentra en la parte de anexos.

Tabla 5: Condicionantes laborales

\begin{tabular}{lll}
\hline Entrevistado & Pregunta & Respuesta \\
\hline Soledad & ¿El tipo de empresa afecta en el puesto & Depende de la disponibilidad del medio \\
Rodríguez & laboral? & para el área, así como de su presupuesto \\
& & para la entrega de múltiples funciones. \\
& & \\
\hline Soledad & ¿Existen presiones en el ámbito laboral? & Siempre que uno labore en medios \\
Rodríguez & & altamente reconocidos tendrá mayor \\
& & presión. Sin embargo, la responsabilidad \\
& & ulterior e individual debe ser siempre la \\
& & misma.
\end{tabular}




$\begin{array}{lll}\begin{array}{l}\text { Martha } \\ \text { Córdova }\end{array} & \begin{array}{l}\text { ¿El tipo de empresa afecta en el puesto } \\ \text { laboral? }\end{array} & \begin{array}{l}\text { No, al contrario, las fuentes y autoridades } \\ \text { saben que laboro en EL Comercio y }\end{array} \\ & \text { conocen de la repercusión que genera una } \\ & \text { noticia publicada en el diario. } \\ \text { Martha } & \text { ¿Existen presiones en el ámbito laboral? } & \text { En lo referente a la comprobación, a } \\ \text { Córdova } & \begin{array}{l}\text { documentar bien la noticia, a contar con } \\ \end{array} & \begin{array}{l}\text { declaraciones de los ámbitos } \\ \text { involucrados y, en cuestión de cierres de }\end{array} \\ & \text { edición. Si la página debe entregarse a las } \\ & 14: 00, \text { es a esa hora. El retraso genera } \\ & \text { complicaciones a la cadena de }\end{array}$

\begin{tabular}{lll}
\hline Anny Rosero & $\begin{array}{l}\text { ¿El tipo de empresa afecta en el puesto } \\
\text { laboral? }\end{array}$ & $\begin{array}{l}\text { No, es más bien una puerta de crecimiento } \\
\text { profesional. }\end{array}$ \\
\hline Anny Rosero & ¿Existen presiones en el ámbito laboral? & $\begin{array}{l}\text { No se las puede consideran presiones, por } \\
\text { el contrario, competencias laborales que }\end{array}$ \\
& & permitan una superación.
\end{tabular}

\begin{tabular}{lll}
\hline $\begin{array}{l}\text { Johana } \\
\text { Calderón }\end{array}$ & ¿El tipo de empresa afecta en el puesto & En este ámbito no afecta mucho el tipo de \\
& laboral? & empresa porque es muy diferente a cómo \\
& & privados con la política. \\
\hline Johana & ¿Existen presiones en el ámbito laboral? & Siempre habrá presiones en el ámbito \\
Calderón & & laboral, pero desde mi experiencia no he \\
& & tenido problemas en cuanto a hablar de \\
& algo que no se quiera.
\end{tabular}

\section{Fuente: elaboración propia.}

Dentro del ámbito laboral, sea cual sea la función que se realice, las personas siempre van a tener presiones, mas no por eso sus trabajos se ven afectados. La preparación de cada una de las periodistas dice mucho de todo lo que cada una de ellas merece. Calderón menciona "desde mi experiencia no he tenido problemas en cuanto a hablar de algo que no se quiera" (J. Calderón, entrevista, 2018) que es algo que concuerda con el testimonio de Rodríguez donde menciona que "no se ve afectada en su puesto laboral porque esto se define de acuerdo con la disponibilidad del medio" (S. Rodríguez, entrevista, 2018). Y, asimismo, cada una de las periodistas fue mencionando que no existe afectación en su puesto de trabajo, cada una de ellas tienen diferentes funciones, viendo esto, como una puerta abierta donde el periodista crece de manera profesional para mantener su puesto. 


\section{Condicionantes ideológicas}

Dentro de las condicionantes laborales se trataron las preguntas 5 y 9 que se encuentra en la parte de anexos.

Tabla 6: Condicionantes ideológicas

\begin{tabular}{|c|c|c|}
\hline Entrevistado & Pregunta & Respuesta \\
\hline $\begin{array}{l}\text { Soledad } \\
\text { Rodríguez }\end{array}$ & $\begin{array}{l}\text { ¿Hay alguna afectación laboral en cuanto } \\
\text { a la ideología de género? }\end{array}$ & $\begin{array}{l}\text { En nuestra ciudad, sí. Aún se evidencia el } \\
\text { machismo en la ubicación del personal en } \\
\text { medios deportivos y en las oportunidades } \\
\text { otorgadas a sus profesionales. }\end{array}$ \\
\hline $\begin{array}{l}\text { Soledad } \\
\text { Rodríguez }\end{array}$ & $\begin{array}{l}\text { ¿Hay algún ámbito que evite que las } \\
\text { mujeres trabajen en deportes, por ser } \\
\text { mujeres? }\end{array}$ & No lo creo. \\
\hline $\begin{array}{l}\text { Martha } \\
\text { Córdova }\end{array}$ & $\begin{array}{l}\text { ¿Hay alguna afectación laboral en cuanto } \\
\text { a la ideología de género? }\end{array}$ & No, existe respeto. \\
\hline $\begin{array}{l}\text { Martha } \\
\text { Córdova }\end{array}$ & $\begin{array}{l}\text { ¿Hay algún ámbito que evite que las } \\
\text { mujeres trabajen en deportes, por ser } \\
\text { mujeres? }\end{array}$ & $\begin{array}{l}\text { No, soy la pionera en el periodismo } \\
\text { deportivo femenino. Lo inicié hace } 35 \\
\text { años, siento que hay mucho respeto a mi } \\
\text { trayectoria. Mi jefe inmediato también } \\
\text { escoge a chicas para los cargos de } \\
\text { pasantes. }\end{array}$ \\
\hline
\end{tabular}

\begin{tabular}{lll}
\hline Anny Rosero & $\begin{array}{l}\text { ¿Hay alguna afectación laboral en cuanto } \\
\text { a la ideología de género? }\end{array}$ & Actualmente no. \\
\hline Anny Rosero & $\begin{array}{l}\text { ¿Hay algún ámbito que evite que las } \\
\text { mujeres trabajen en deportes, por ser } \\
\text { mujeres? }\end{array}$ & \\
\hline Johana & ¿Hay alguna afectación laboral en cuanto & Siempre habrá diferencia y afectación en \\
Calderón & a la ideología de género? & el género femenino, ya que siempre \\
& & $\begin{array}{l}\text { estuvo el estereotipo de que el fútbol es } \\
\text { solamente para hombres. Creo que uno se }\end{array}$ \\
& gana todo con capacidad, el respeto en \\
& todo el ámbito deportivo. Una mujer debe \\
& prepararse el triple a comparación de un \\
& hombre. Una mujer no & puede \\
& &
\end{tabular}




\begin{tabular}{lll}
\hline Johana & ¿Hay algún ámbito que evite que las & En la actualidad, no. Por el desarrollo de \\
Calderón & mujeres trabajen en deportes, por ser las mujeres, en donde se han ganado cada \\
& mujeres? & espacio en todos los aspectos \\
& profesionales.
\end{tabular}

\section{Fuente: elaboración propia.}

Para esto, es importante mencionar, citando las palabras de Rodríguez, que, "en nuestra ciudad, sí, aún se evidencia el machismo en la ubicación del personal en medios deportivos y en las oportunidades otorgadas a sus profesionales" (S. Rodríguez, entrevista, 2018). Asimismo, sigue existiendo ese aspecto en el que se dice que las mujeres no pueden trabajar en este ámbito y creo que para que esto desaparezca, la sociedad debe dejar de ser o dejar de llevarse por aspectos machistas, deberían admitir que las mujeres son tan capaces de dar la información en cuando a fútbol se refiera, que de la manera en la que lo haría un hombre.

Pero, a pesar de esto, las periodistas deportivas mujeres se encuentran tan bien preparadas que no hace falta prohibir o exigir más a ellas que a hombres, porque ellas están dispuestas a prepararse tanto que su margen de error sea nulo. Es imposible mencionar que las personas son capaces de cometer errores, por el mismo hecho de ser personas, todos los seres humanos tienen derecho a equivocarse.

\section{Condicionantes Jerárquicas}

Dentro de las condicionantes jerárquicas se trataron las preguntas 6,7 y 8 que se encuentra en la parte de anexos.

Tabla 7: Condicionantes jerárquicas

\begin{tabular}{|c|c|c|}
\hline Entrevistado & Pregunta & Respuesta \\
\hline $\begin{array}{l}\text { Soledad } \\
\text { Rodríguez }\end{array}$ & ¿Existe alguna jerarquía en el trabajo? & $\begin{array}{l}\text { Por supuesto. Las jerarquías parten no } \\
\text { sólo por escala económica o salarial sino, } \\
\text { sobre todo, por la experiencia de sus } \\
\text { profesionales. }\end{array}$ \\
\hline $\begin{array}{l}\text { Soledad } \\
\text { Rodríguez }\end{array}$ & $\begin{array}{l}\text { ¿La jerarquía se ve afectada por si se es } \\
\text { mujer y hombre? }\end{array}$ & En ocasiones sí. \\
\hline $\begin{array}{l}\text { Soledad } \\
\text { Rodríguez }\end{array}$ & $\begin{array}{l}\text { ¿La jerarquía organizacional se afecta por } \\
\text { el género? }\end{array}$ & $\begin{array}{l}\text { En nuestro país lamentablemente aún } \\
\text { influye eso en el organigrama de las } \\
\text { instituciones. }\end{array}$ \\
\hline $\begin{array}{l}\text { Martha } \\
\text { Córdova }\end{array}$ & ¿Existe alguna jerarquía en el trabajo? & $\begin{array}{l}\text { Existe un organigrama como en toda } \\
\text { empresa, con autoridades, equipo de } \\
\text { trabajo. }\end{array}$ \\
\hline
\end{tabular}




\begin{tabular}{ll}
\hline $\begin{array}{l}\text { Martha } \\
\text { Córdova }\end{array}$ & $\begin{array}{l}\text { ¿La jerarquía se ve afectada por si se es } \\
\text { mujer y hombre? }\end{array}$ \\
\hline $\begin{array}{l}\text { Martha } \\
\text { Córdova }\end{array}$ & $\begin{array}{l}\text { ¿La jerarquía organizacional se afecta por } \\
\text { el género? }\end{array}$
\end{tabular}

\begin{tabular}{|c|c|c|}
\hline Anny Rosero & ¿Existe alguna jerarquía en el trabajo? & $\begin{array}{l}\text { Si, como en la mayoría de los trabajos la } \\
\text { organización es la misma. }\end{array}$ \\
\hline Anny Rosero & $\begin{array}{l}\text { ¿La jerarquía se ve afectada por si se es } \\
\text { mujer y hombre? }\end{array}$ & $\begin{array}{l}\text { En la actualidad ya no, se respeta de igual } \\
\text { manera el poderío que pueda existir entre } \\
\text { los diversos géneros. }\end{array}$ \\
\hline
\end{tabular}

\begin{tabular}{lll}
\hline Anny Rosero & $\begin{array}{l}\text { ¿La jerarquía organizacional se afecta por } \\
\text { el género? }\end{array}$ & $\begin{array}{l}\text { No, cada persona tiene clara las funciones } \\
\text { que debe cumplir y los plazos en los que } \\
\text { se debe entregar el trabajo. }\end{array}$ \\
\hline Johana & ¿Existe alguna jerarquía en el trabajo? & $\begin{array}{l}\text { Jerarquía existe en todo trabajo. Ante } \\
\text { todo, creo que se llama respeto. Respeto } \\
\text { Calderón }\end{array}$ \\
& $\begin{array}{l}\text { hacia las personas que llevan varios años } \\
\text { en su puesto. Siempre hay que demostrar }\end{array}$ \\
& $\begin{array}{l}\text { que tienes las condiciones y capacidad } \\
\text { para ser una gran periodista deportiva. }\end{array}$
\end{tabular}

\begin{tabular}{lll}
\hline $\begin{array}{l}\text { Johana } \\
\text { Calderón }\end{array}$ & $\begin{array}{l}\text { ¿La jerarquía se ve afectada por si se es } \\
\text { mujer y hombre? }\end{array}$ & $\begin{array}{l}\text { Anteriormente, sí. Ahora creo que no } \\
\text { porque las mujeres se han ganado la } \\
\text { jerarquía por sus condiciones y sus } \\
\text { capacidades. }\end{array}$ \\
\hline Johana & ¿La jerarquía organizacional se afecta por & No tiene mucho que ver el género porque \\
Calderón & el género? & $\begin{array}{l}\text { creo que las mujeres se han ido ganando } \\
\text { su espacio al igual que los hombres. }\end{array}$
\end{tabular}

\section{Fuente: elaboración propia.}

Las jerarquías laborales en cualquier trabajo siempre van a existir, solo se basan dentro de los organigramas que se plantee cada empresa. A pesar de esto, las mujeres en la actualidad, no se ven afectadas por esto, más bien, ahora, las mujeres se han ganado tanto su puesto de trabajo demostrando lo que son, lo que valen y la preparación que tienen, de tal manera en que no se ven afectadas de ninguna manera en roles ni jerarquías organizacionales.

\section{Presión Social}


Dentro de las condicionantes de presión social se trataron las preguntas $12,13 \mathrm{y}$ 14 que se encuentra en la parte de anexos.

Tabla 8: Presión social

\begin{tabular}{lll}
\hline Entrevistado & Pregunta & Respuesta \\
\hline Soledad & ¿Existe presión de la sociedad al trabajo & Muchísima. La mujer tiene poco o nulo \\
Rodríguez & realizado por periodistas deportivas & margen de error. Pierden rápido la \\
& mujeres? & $\begin{array}{l}\text { credibilidad por la perspectiva machista } \\
\text { del público y entorno profesional. }\end{array}$ \\
& & \\
\hline Soledad & ¿La audiencia exige presión sobre lo que & Poca. En algunas ocasiones piden temas o \\
Rodríguez & se va a informar? & sugieren mediante líneas telefónicas o \\
& & redes sociales, pero no marcan la pauta \\
& & real.
\end{tabular}

\begin{tabular}{lll}
\hline $\begin{array}{l}\text { Soledad } \\
\text { Rodríguez }\end{array}$ & $\begin{array}{l}\text { ¿El medio en el que se trabaja plantea } \\
\text { presión en la periodista por el hecho de } \\
\text { ser mujer? }\end{array}$ & $\begin{array}{l}\text { Sí. Especialmente en Tv donde la mujer } \\
\text { no sólo puede equivocarse pronto sino se } \\
\text { privilegia siempre su imagen por encima } \\
\text { de su capacidad. }\end{array}$ \\
\hline Martha & ¿Existe presión de la sociedad al trabajo & Personalmente no lo he sentido. Al \\
Córdova & realizado por periodistas deportivas & contrario, muchas personas: \\
& mujeres? & $\begin{array}{l}\text { entrenadores, deportistas y dirigentes } \\
\text { destacan el trabajo realizado. }\end{array}$
\end{tabular}

\begin{tabular}{ll}
\hline $\begin{array}{l}\text { Martha } \\
\text { Córdova }\end{array}$ & $\begin{array}{l}\text { ¿La audiencia exige presión sobre lo que } \\
\text { se va a informar? }\end{array}$ \\
\hline $\begin{array}{l}\text { Martha } \\
\text { Córdova }\end{array}$ & $\begin{array}{l}\text { ¿El medio en el que se trabaja plantea No. } \\
\text { presión en la periodista por el hecho de } \\
\text { ser mujer? }\end{array}$ \\
\end{tabular}

\begin{tabular}{lll}
\hline Anny Rosero & ¿Existe presión de la sociedad al trabajo & Sí, es imposible olvidar que antiguamente \\
& $\begin{array}{l}\text { realizado por periodistas deportivas } \\
\text { mujeres? }\end{array}$ & $\begin{array}{l}\text { este campo lo manejaban en su totalidad } \\
\text { los hombres, lo que nos exige como } \\
\end{array}$ \\
& & $\begin{array}{l}\text { mujeres, estudiar más, leer, investigar y } \\
\text { estar un paso delante de nuestros colegas } \\
\text { deportivos hombre, ya que si la audiencia } \\
\text { nos critica más que a ellos. }\end{array}$ \\
\hline Anny Rosero & ¿La audiencia exige presión sobre lo que & $\begin{array}{l}\text { Sí, en ciertos casos cuando se brinda } \\
\text { información de algún equipo en especial, }\end{array}$ \\
& se va a informar? & se debe cuidar muy bien los términos que \\
\hline
\end{tabular}




\begin{tabular}{|c|c|c|}
\hline & & $\begin{array}{l}\text { se va a utilizar para no herir } \\
\text { susceptibilidades y tampoco para generar } \\
\text { polémica mal fundamentada. }\end{array}$ \\
\hline Anny Rosero & $\begin{array}{l}\text { ¿El medio en el que se trabaja plantea } \\
\text { presión en la periodista por el hecho de } \\
\text { ser mujer? }\end{array}$ & $\begin{array}{l}\text { Más bien exigencia en presenta un trabajo } \\
\text { más elaborado y con un margen de error } \\
\text { nulo. }\end{array}$ \\
\hline $\begin{array}{l}\text { Johana } \\
\text { Calderón }\end{array}$ & $\begin{array}{l}\text { ¿Existe presión de la sociedad al trabajo } \\
\text { realizado por periodistas deportivas } \\
\text { mujeres? }\end{array}$ & $\begin{array}{l}\text { Sí existe presión de la sociedad y } \\
\text { audiencia. Porque la mujer no puede } \\
\text { equivocarse, teniendo que prepararse el } \\
\text { triple. Los errores de las mujeres serán } \\
\text { recordados por siempre porque se cree } \\
\text { que las mujeres no están en la capacidad } \\
\text { de hablar de fútbol, al igual que lo puede } \\
\text { hacer un hombre. }\end{array}$ \\
\hline $\begin{array}{l}\text { Johana } \\
\text { Calderón }\end{array}$ & $\begin{array}{l}\text { ¿La audiencia exige presión sobre lo que } \\
\text { se va a informar? }\end{array}$ & $\begin{array}{l}\text { La audiencia exige presión al informar } \\
\text { cosas reales. Es cierto, porque la función } \\
\text { del periodista es darle a la audiencia } \\
\text { información real y mantenerlos } \\
\text { informados. Esta presión es común } \\
\text { porque el deber del periodista es informar } \\
\text { con la verdad. }\end{array}$ \\
\hline $\begin{array}{l}\text { Johana } \\
\text { Calderón }\end{array}$ & $\begin{array}{l}\text { ¿El medio en el que se trabaja plantea } \\
\text { presión en la periodista por el hecho de } \\
\text { ser mujer? }\end{array}$ & $\begin{array}{l}\text { No, en los medios que yo he trabajado no } \\
\text { he tenido presión de hacer algo de mejor } \\
\text { manera por ser mujer. Creo que eso se } \\
\text { debe a las condiciones que he demostrado } \\
\text { para llegar a mi trabajo. }\end{array}$ \\
\hline
\end{tabular}

\section{Fuente: elaboración propia.}

Es importante mencionar que la presión social, definida como: "tipo de influencia social en el que los individuos cambian sus actitudes o comportamientos para adherirse a las normas sociales existentes" (Rodríguez, 2016, párr. 1), sobre las periodistas deportivas mujeres, siempre existirá y no solo por parte de la sociedad en general, sino por la audiencia que cada una de ellas posee en los diferentes medios. Con la manera de pensar un tanto machista de cada una de las personas, obviamente no de todos, ha dejado marcada la diferencia entre los periodistas deportivos hombres y mujeres. Por lo tanto, se menciona que los hombres son capaces de tener ciertos errores en lo que mencionan, los cuales, posteriormente serán olvidados. Pero, a diferencia de ellos, las mujeres no pueden cometer errores, en caso de tenerlos, estos serán recordados por siempre y la credibilidad en ellas se perderá. 
Rosero tiene razón al mencionar: "es imposible olvidar que antiguamente este campo lo manejaban en su totalidad los hombres, lo que nos exige como mujeres, estudiar más, leer, investigar y estar un paso delante de nuestros colegas deportivos hombre, ya que si la audiencia nos critica más que a ellos" (A. Rosero, entrevista, 2018). Y esto se ha visto reflejado en la preparación y formación continua que cada una de las periodistas ha ido adquiriendo a lo largo de los años en las labores que realizan. No siempre sabrán todo, pero están completamente claras que las personas, la audiencia, el público, los lectores, merecen información inmediata y verídica, que con la preparación que han adquirido, son capaces de lograr brindar.

\section{Discusión}

El punto por recalcar en esta investigación es el hecho de que la sociedad se ha visto acostumbrada al consumo de noticias en televisión, redes o radio, realizadas por periodistas deportivos hombres, aquellos que gritan los goles desde el fondo de su corazón, pero, se menciona que la situación a tomar en cuenta es que la misma labor la pueden hacer las mujeres: "en los albores de la feminización a la que actualmente estamos asistiendo, las mujeres periodistas mostraron una nueva forma de hacer periodismo, hasta el punto de que modificaron la manera de acceder a las fuentes informativas" (Ufarte, 2007, párr. 9). De tal manera, en estos tiempos, ha existido una inserción en esta rama del periodismo, donde las mujeres que han ido trabajando en cada aspecto mediático, ha demostrado que, si se tiene una manera diferente de realizar las cosas, también es una manera de evidenciar que si algo no es como se ha acostumbrado la sociedad, no quiere decir que esté mal.

Simultáneamente, se dice que las mujeres al abrirse espacios de trabajo en el periodismo deportivo cambian la manera en la que se organiza un medio; "la feminización del Periodismo supone hoy uno de los ámbitos de investigación de mayor interés, por las consecuencias que puede tener sobre las carreras de las licenciadas y los licenciados, así como en las modificaciones que pueda acarrear en la conformación de las redacciones de los medios de comunicación" (Santamarina, 2014, p. 261). Entonces, se menciona que el periodismo es aquella profesión en la que, tomando en cuenta la realidad actual, tanto las licenciadas como licenciados, adquieren los mismos derechos de redacción, locución, edición, etc.

Aunque, cabe mencionar, que anteriormente, debido a un acto que la sociedad conoce como "machismo", las mujeres periodistas en el ámbito deportivo tuvieron que cambiar su manera de ver y realizar su trabajo. Merchán, periodista del diario El Telégrafo, mencionó que, debido a ese machismo mencionado, las periodistas tuvieron una cantidad elevada de desventaja frente a sus colegas, aquellos que no sentían rechazo por parte de la audiencia, rechazo que ellas sí poseían no solo por los aficionados, sino por sus mismos colegas, quienes mencionaban, sin criterio completamente formado, que una mujer no puede sobresalir en el periodismo deportivo (Merchán, 2015, párr. 5). 
De esta manera, como menciona Calderón en la tabla 6 (ver anexo el cuestionario), "La audiencia exige presión al informar cosas reales. Es cierto, porque la función del periodista es darle a la audiencia información real y mantenerlos informados. Esta presión es común porque el deber del periodista es informar con la verdad" (J. Calderón, entrevista, 2018); sin embargo, de debe siempre tomar en cuenta a la inmediatez que se obtiene por informar. Si bien es cierto, algunos medios prefieren sacar una noticia que se encuentra en boga en un momento determinado, aunque no todas las ocasiones dicha noticia sea verdadera. Siempre se debe evitar generar fake news, y aunque se pierda el momento de algún hecho, es preferible tener la información verificada a una información sin verificar, pero del momento.

Si el fútbol o el deporte en general, no ha modificado la manera de practicarse, no es posible esperar que la manera de informar sea diferente. Hay que tomar en cuenta que varios han sido los equipos deportivos que han implementado categorías femeninas, como en equipos pertenecientes a la MLS (Major League Soccer), que, a pesar de tener un equipo femenino, la manera de practicar el deporte no cambia. "Una buena paradoja entraña el periodismo deportivo: siendo la primera expresión acabada del periodismo especializado, constituye una de las modalidades periodísticas que menos han evolucionado al paso del tiempo"(Domínguez, 2015, párr. 2). Menos han evolucionado porque el deporte no se ha modificado, aunque la manera de expresarlo sí cada vez existe más inclusión a periodistas mujeres.

Por la razón de existencia de la web 2.0 y de las redes sociales, cabe mencionar que "cuando la velocidad se impone como horizonte último del periodismo, se acaban descuidando valores deontológicos fundamentales como el de crear información veraz, plural y contrastada" (Cedillo \& Barranquero, 2015, p. 452). Si se impone velocidad al momento que se adquiere la información, debe imponerse la velocidad dentro de la formación del periodista. Un periodista aprende leyendo y de sus colegas. Existe la prueba y el error, pero hay que tomar en cuenta que ese margen de error debe ser casi nulo, por el hecho de que, como mencionaba en la tabla 6 (ver cuestionario en anexos), "Sí existe presión de la sociedad y audiencia. Porque la mujer no puede equivocarse, teniendo que prepararse el triple. Los errores de las periodistas serán recordados por siempre porque se cree que ellas no están en la capacidad de hablar de fútbol, al igual que lo puede hacer un hombre" (J. Calderón, entrevista, 2018). Se recalca la importancia de la preparación de la periodista deportiva mujer, preparación para la cual su margen de error sea nulo. Se menciona nulo, porque si la periodista es capaz de equivocarse en algún aspecto informativo, la audiencia a la que dirige su información, no le brindará la aceptación necesaria, como lo harían si un periodista deportivo hombre comete algún error.

Finalmente, es importante observar la inserción de las periodistas deportivas mujeres en los medios, medios que han ido evolucionando, pero, "a pesar de que la inclusión de mujer en el ámbito del periodismo deportivo aún sigue siendo un problema en algunos medios, la mujer ha luchado por incursionar en esta área desde hace varias décadas"(Covarrubias, 2009, párr. 4). Este problema va más allá de lo que se puede mencionar, porque no se trata solo de la formación que recibe la periodista para trabajar 
en un medio, sino, de la formación que recibe la audiencia para poder entender que una mujer puede amar, practicar e informar de manera excelente en Periodismo Deportivo, como lo haría un hombre. No es solo el hecho de que se prepare a las profesionales, sino, prepararse la sociedad para adaptarse a aquello que no solía hacerlo, mencionando siempre el profesionalismo de las periodistas deportivas mujeres que dejan de lado cualquier tipo de condicionante, ya sea laboral, jerárquica e ideológica además de evitar dejarse llevar por la presión social que existe. Tanto mujer como hombre es un profesional digno de trabajar en el ámbito del periodismo deportivo, esto quiere decir, que el género no define la calidad de información que pueda presentar.

\section{Conclusiones}

Es importante mencionar que las rutinas periodísticas llevadas a cabo por las periodistas entrevistadas se caracterizan por una formación continua y personalizada en todo momento, por lectura de libros, noticias y redes sociales. Sin la web 2.0 la comunicación no hubiera avanzado de manera significante como lo ha hecho hasta ahora, las personas no tendrían la capacidad de investigar y seguirse educando día a día; el trabajo que realizan las periodistas deportivas mujeres en un mundo donde todos saben de todo, pero a la vez, no profundizan en nada, es algo admirable.

Por otro lado, cabe recalcar que tanto los periodistas deportivos hombres y mujeres, tienen y merecen el respeto de toda la sociedad, ambos se han preparado para pertenecer y obtener un trabajo digno, un trabajo que sea reconocido por todos aquellos amantes de un deporte o amantes de la información. En una sociedad donde todo está al alcance de todos, se evidencia la importancia de saber diferenciar qué sirve y qué no sirve, de esa manera serán capaces de admitir que los periodistas son humanos y pueden tener cualquier error y no por eso terminar con su carrera. Además, es la misma sociedad aquella que deberá cambiar el pensamiento que posee, por un pensamiento en el que se reconozca el trabajo de las periodistas deportivas mujeres, las rutinas periodísticas que llevan a cabo y la formación que poseen, por un trabajo tan excelente como puede serlo el de un periodista deportivo hombre. Si cambia la sociedad esa manera de pensar, el trabajo que las periodistas realizan será llevado a cabo de mejor manera, sin temores al fracaso y a ser rechazadas por toda la probación masculina.

Respondiendo con los objetivos de la investigación, se determinó que la práctica que poseen las periodistas deportivas mujeres, la formación que poseen y los logros que han conseguido ha sido gracias a su aporte con los medios en los que cada una trabaja, teniendo un amplio conocimiento del periodismo deportivo y aprendiendo día a día, filtrando información, además de un autoaprendizaje con base en el medio al que cada una de las periodistas pertenece. De igual manera, se logró señalar que las rutinas periodísticas que se llevan a cabo para radio son llevadas a cabo según la inmediatez de la información y la coyuntura que las noticias presentan, sin dejar de lado el llegar directamente a la fuente necesaria para verificar cualquier tipo de información. Finalmente, se evaluaron las condicionantes que interfieren en el trabajo de cada una de las periodistas deportivas y se determinó que lo que más influye es la presión social y el 
pensamiento que cada individuo de la sociedad posee, un pensamiento en el que se deja de lado el profesionalismo de las periodistas simplemente por creer que las periodistas deportivas mujeres no están tan bien preparadas como lo estaría un periodista deportivo hombre.

Por consiguiente, respondiendo a la pregunta que se planteó al principio de la investigación, ¿en qué medida se ven afectadas las rutinas periodísticas de periodistas deportivas mujeres de Quito por las condicionantes ideológicas, jerárquicas, laborales y la presión social? Es importante decir que, si se habla de problemas planteados por condiciones ideológicas, todavía son existentes, exigen mayor rendimiento por parte de las periodistas, mayor que el del hombre porque, la formación de la audiencia sigue siendo aquella en la que se piensa que las periodistas deportivas mujeres no pueden o no son las mejores para el puesto, por el simple hecho de ser mujeres. En cuanto a condicionantes jerárquicas y laborales queda establecido que las plazas de trabajo han abierto sus puertas a las profesionales, porque ellas han demostrado que su formación periodística es apta para el puesto, al que deben regirse por un jefe, pero esto, no afecta en nada. Y, la presión social, siempre existirá, las personas tendrán que cambiar su forma de pensar, su forma de actuar y la forma de expresarse ante el trabajo que realizan las mujeres en cuanto a periodismo, si ellas se ven preparadas en el periodismo para tener un margen de error nulo, merecen el puesto de trabajo igual que cualquier periodista deportivo hombre.

\section{Bibliografía}

Benítez, D., \& Espinosa, B. (2018). Discriminación salarial por género en el sector formal en Ecuador usando registros administrativos, 25.

Burch, S. (1995). Género y comunicación: La agenda de las mujeres en comunicación para el nuevo siglo, 10.

Cedillo, G., \& Barranquero, A. (2015). Periodismo lento (slow journalism) en la era de la inmediatez. Experiencias en Iberoamérica. El Profesional de la Información, 24, 451. https://doi.org/10.3145/epi.2015.jul.12

Covarrubias, R. (2009). El ejercicio profesional de la mujer dentro del Periodismo Deportivo. Recuperado 11 de julio de 2018, de http://www.redalyc.org/html/1995/199520330056/

Domínguez, J. (2015). Ensayo sobre la cuádruple espectacularidad del Periodismo Deportivo. Recuperado 11 de julio de 2018, de http://www.redalyc.org/html/1995/199520330048/

Fernández, I. (2017, agosto 1). Fake news: cómo detectarlas. Recuperado 23 de julio de 2018, de https://www.mediatrends.es/a/128942/fake-news-en-espanol-definitionexamples-significado-que-significa-como-detectarlas/ 
Masip, P. (2013). Rutinas periodísticas e internet en la información diaria, 561-576.

Méndez, S. (2015). El reto formativo en tecnologías para el periodismo deportivo. Recuperado 11 de julio de 2018, de http://www.redalyc.org/html/310/31043005025/

Merchán, J. (2015, diciembre 6). Las mujeres también ejercen el periodismo deportivo. Recuperado 11 de julio de 2018, de https://www.eltelegrafo.com.ec/noticias/2015/10/las-mujeres-tambien-ejercenel-periodismo-deportivo

Mingo, E. (2005). Problema de investigación, 20.

Pedraza, C. (2012). Mujeres en el Periodismo Deportivo: Reflexiones para comprender la transfresión desde la práctica discursiva de las reporteras de deportes, 24.

Proaño, L. E. (2005). Carta del Editor. Chasqui. Revista Latinoamericana de Comunicación, $0(90), 1$.

Rodríguez, C. (2016, marzo 8). La presión social: ¿Una fuerza irresistible? | Guioteca.com. Recuperado 23 de julio de 2018, de https://www.guioteca.com/psicologia-y-tendencias/la-presion-social-una-fuerzairresistible/

Rojas, J. L. (2010). La consrucción de las noticias deportivas desde una mirada androcéntrica. De la invisibilidad a los estereotipos de la mujer deportista, 15.

Santamarina, D. R. (2014). División sexual del periodismo. Ellas a las aulas y ellos a las redacciones: estudio del caso vasco. Cuestiones de género: de la igualdad y la diferencia, $0(9), 259-285$.

Ufarte, M. J. (2007). Las mujeres en el seno de la profesión periodística: de la discrimi... Recuperado 11 de julio de 2018, de http://www.redalyc.org/html/168/16801623/

Vásquez, A. B., \& Rivadeneira, C. O. (2012). Ajunto primero del Defensor del Pueblo, 45.

Vivar, F., \& Miguel, J. (2009). Nuevos modelos de comunicación, perfiles y tendencias en las redes sociales. Comunicar, XVII(33), 74-81. 